\title{
CONOTRUNCAL REPAIR FOR TETRALOGY OF FALLOT: MIDTERM RESULTS
}

Hiromi Kurosawa, MD

Kiyozo Morita, $\mathrm{MD}^{\mathrm{a}}$

Masaaki Yamagishi, MDa

Shogo Shimizu, MD

Anton E. Becker, $\mathrm{MD}^{\mathrm{b}}$

Robert H. Anderson, MD

Sponsor:

Edward L. Bove, MD
Objective: Because of the left-sided location of the main atrioventricular conduction axis, the membranous flap can be safely used for closure of the ventricular septal defect in tetralogy of Fallot. Methods: Conotruncal repair consists of (1) precise closure of the defect using the membranous flap and (2) outflow reconstruction of the right ventricle by a wide monocusp patch. This method has been followed in 233 patients from October 1985 to March 1997. The age of patients ranged from 2 months to 53 years, with a mean of 4.6 years; $44 \%$ were younger than 2 years of age, and $11 \%$ were less than 12 months of age. Results: A membranous flap was present in $86 \%, 12 \%$ had a muscle bar between the defect and the tricuspid valve, and only $2 \%$ had neither a membranous flap nor a muscle bar. There was no early death; two late deaths occurred over a mean follow-up period of 7.3 years. The actuarial survival was $\mathbf{9 9 . 1 \%}$. No patients required reoperation except for two with residual anomalously connecting pulmonary veins. All 233 patients were in sinus rhythm postoperatively. No patient has had a significant residual defect. The mobility of the polytetrafluoroethylene monocusp was echocardiographically detected in $85 \%$ and pulmonary regurgitation was less than mild in $82 \%$ at the late phase. The late right and left ventricular pressure ratio was $0.40 \pm 0.14(n=30)$ and the late central venous pressure was $5.6 \pm 2.2 \mathrm{~mm} \mathrm{Hg}(n=30)$. Conclusion: Conotruncal repair has provided good midterm results with a low central venous pressure, well-reconstructed outflow tract of the right ventricle, no residual defect, and no heart block. (J Thorac Cardiovasc Surg 1998;115:351-60)
$\mathrm{T}_{\mathrm{te}}^{\mathrm{he}}$ he ultimate goal set for the surgical repair of tetralogy of Fallot is a low central venous pressure (CVP), no heart murmur, and no conduction disturbance. To achieve this objective, conotruncal repair was introduced in $1985 .^{1}$ The purpose of this

From the Department of Cardiovascular Surgery, Jikei Univer-

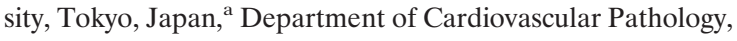
Academic Medical Center, University of Amsterdam, Amsterdam, The Netherlands, ${ }^{\mathrm{b}}$ Department of Pediatrics, Imperial College School of Medicine at the National Heart \& Lung Institute, Royal Brompton Hospital, London, United Kingdom, ${ }^{\mathrm{c}}$ and the University of Michigan, Ann Arbor, Mich.

Read at the Seventy-seventh Annual Meeting of The American Association for Thoracic Surgery, Washington D.C., May 4-7, 1997.

Received for publication May 6, 1997; revisions requested June 10, 1997; revisions received Sept. 5, 1997; accepted for publication Sept. 8, 1997.

Address for reprints: Hiromi Kurosawa, MD, Department of Cardiovascular Surgery, Jikei University, 3-25-8 Nishi-Shinbashi, Minato-ku, Tokyo 105, Japan.

Copyright (c) 1998 by Mosby, Inc.

$0022-5223 / 98 \$ 5.00+0 \quad \mathbf{1 2 / 6 / 8 5 9 9 7}$ communication is to report the midterm results of this repair.

\section{Methods}

Conotruncal repair. Conotruncal repair consists of (1) precise closure of the ventricular septal defect (VSD) with the membranous flap instead of the septal leaflet of the tricuspid valve and (2) reconstruction of the right ventricular outflow tract by a transannular patch with a wide monocusp. Because the septal leaflet of the tricuspid valve, which is a part of the inlet of the right ventricle, is not used for closure of the VSD and a patch infundibuloplasty is short, both procedures are performed entirely within the "conotruncal portion (or outlet component)" of the right ventricle (Fig. 1). This method has been followed in 233 patients with tetralogy of Fallot seen from October 1985 to March 1997. Meanwhile another 22 patients underwent total correction by transatrial approach without a transannular patch or external conduit, and they were not included in this study. The patients with a nonobstructed tricuspid pulmonary valve and only obstruction of the muscular infundibulum, who were usually acyanotic, underwent repair by the transatrial approach without ventriculotomy. These patients were not included in this study. Conotruncal repair with the monocusp patch was adopted only for patients who had an obstructed or atretic pulmonary valve. 


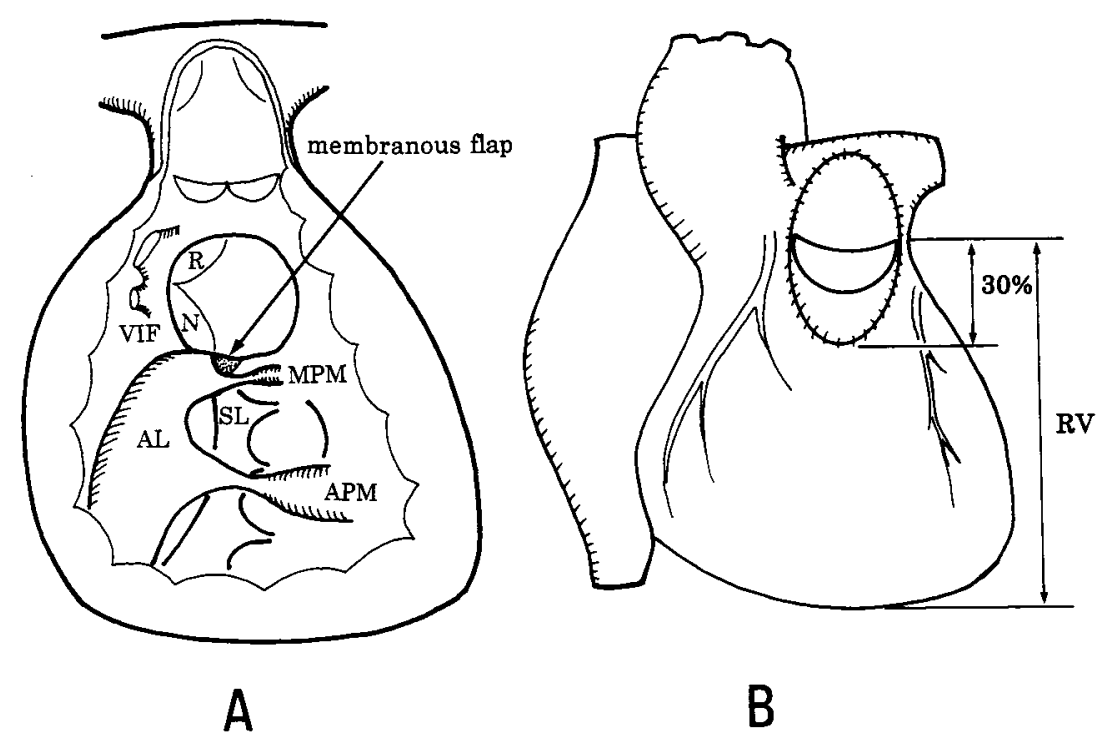

Fig. 1. Conotruncal repair. Closure of the VSD and patch reconstruction of the outflow tract are performed within the conotruncal (outlet) portion. A, The posteroinferior border of the perimembranous outlet VSD consists of the ventriculoinfundibular fold $(V I F)$, the anulus of the anterior leaflet of the tricuspid valve $(A L)$ corresponding to the fibrous continuity with the aortic noncoronary cusp $(N)$, the membranous flap, and the posterior extension of the septomarginal trabeculation (see Fig. 4, A). The septal leaflet of the tricuspid valve (SL) is a part of the inlet of the right ventricle and is not used. Muscle bundles are resected and left as muscle stumps in VIF. B, The length of patch infundibuloplasty is less than $30 \%$ of the length of the right ventricle $(R V)$. MPM, Medial papillary muscle; $A P M$, anterior papillary muscle; $R$, right coronary cusp of the aortic valve.

The most common type of VSD in Fallot's tetralogy is a perimembranous outlet defect in which the posteroinferior border of the defect is directly continuous with the central fibrous body; in a minority of hearts only a muscle bar intervenes between the VSD and the tricuspid valve. ${ }^{2}$ In cases with the muscle bar formed by fusion of the posterior extension of the septomarginal trabeculation and the ventriculoinfundibular fold, a pledget-supported suture is placed in the muscle bar. An "interventricular" membranous flap, often continuous with the medial papillary muscle, exists at the posteroinferior border of the perimembranous outlet VSD in most hearts.

In cases with the membranous flap, the anulus of the tricuspid septal leaflet comes up to the posterior end of the flap (Fig. 2, $A$ ). The VSD extends transversely toward the apex and is remote from the attachment of the septal leaflet of the tricuspid valve. Both are separated by a membranous flap. In fact, the existence of such an "interventricular" membranous flap relates to this particular anatomic feature, which at the same time reduces the size of the "atrioventricular" membranous septum. A thick posterior extension of the septomarginal trabeculation, which supports the medial papillary muscle, covers the right aspect of the branching bundle. Hence, the membranous flap stays remote from the conduction axis ${ }^{3}$ (Fig. 3, A) and can be used safely for patching the VSD. ${ }^{4} \mathrm{~A}$ pledget-supported suture is placed through the membranous flap ${ }^{4}$ (Number 1 suture in Fig. 4, $A$, and 5). On the other hand, in hearts without a membranous flap, the
VSD extends inferiorly and the anulus of the tricuspid septal leaflet comes up anteriorly where it crosses the tapered end of a thin posterior extension of the septomarginal trabeculation. Therefore the "interventricular" membranous flap is absent and the "atrioventricular" membranous septum is large (Fig. 2, B). In these instances, therefore, the branching bundle runs in close apposition to the atrioventricular membranous septum, whereas the bifurcating bundle appears on the inferior border of the defect (Fig. 3, B). The atrioventricular membranous septum should not be mistaken for a membranous flap, and sutures should not be placed in the lowest part of this area (Fig. 4, B). When fibrous continuity exists between the noncoronary aortic cusp and the anterior leaflet of the tricuspid valve, separating the ventriculoinfundibular fold from the membranous flap, several sutures are stitched from the right atrial aspect along this area, which corresponds with a part of the "anterior anulus" of the tricuspid valve (Number 4 suture in Figs. 4 and 5).

Patch closure of the VSD was accompanied by sufficient resection of hypertrophied muscle bundles at the site of the ventriculoinfundibular fold. In the initial series the hypertrophied infundibular (outlet) septum was totally resected, ${ }^{1}$ but it was subtotally resected in the recent series because a wider monocusp was used than before. An adequate visualization of the VSD can be obtained through a short ventriculotomy if the muscular connection between the infundibular septum and the ventriculoinfun- 


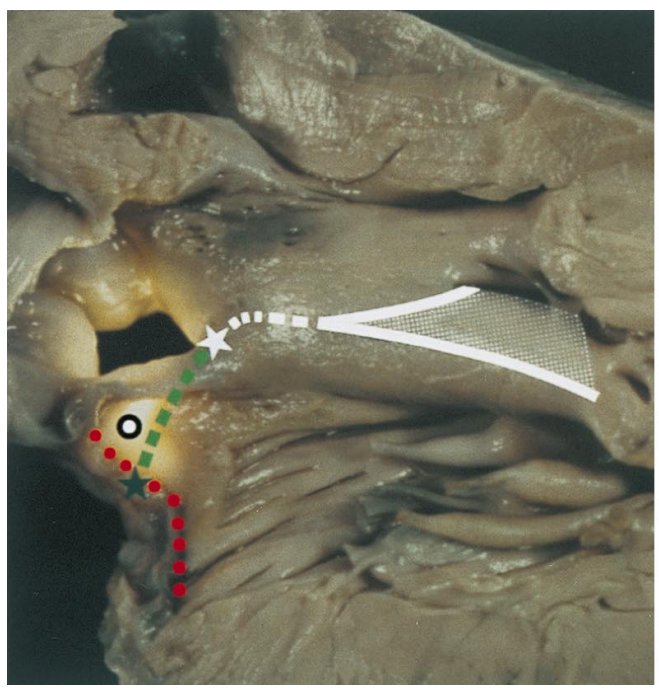

A

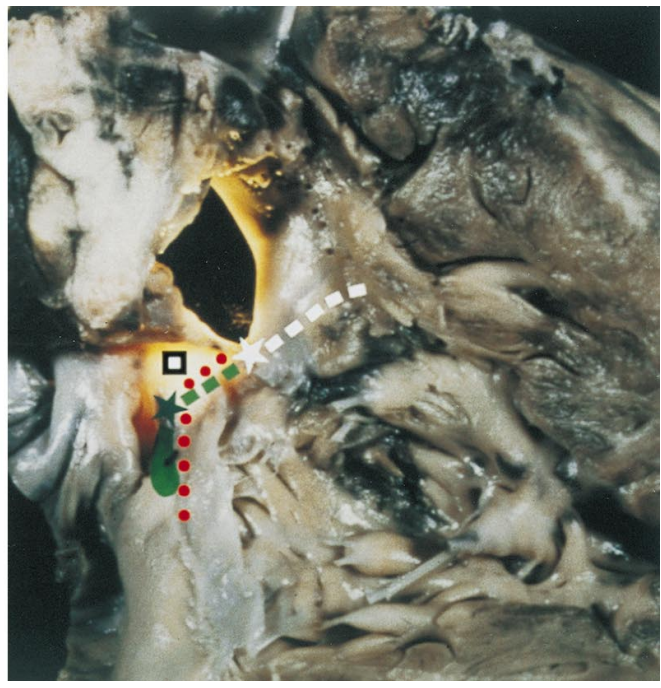

B

Fig. 2. The location of the main conduction axis in tetralogy of Fallot. A, Case with a membranous flap. The VSD extends transversely toward the apex and is remote from the attachment (indicated by dotted red line) of the septal leaflet of the tricuspid valve. The interventricular membranous flap interposes between the VSD and the septal leaflet of the tricuspid valve and is fused with the medial papillary muscle. B, Case without a membranous flap. The VSD extends inferiorly and approximates to the attachment (indicated by dotted red line) of the septal leaflet of the tricuspid valve. The membranous flap disappears between the VSD and the septal leaflet. Green asterisk = penetrating bundle; green dotted line = branching bundle; white asterisk = bifurcating bundle; white dotted line = intramural right bundle branch; white solid line = subendocardial right bundle branch; red dotted line = anulus of the septal leaflet of the tricuspid valve; $\bigcirc$ $=$ "interventricular" membranous flap; $\square=$ "atrioventricular" membranous septum.

dibular fold is divided in front of the aortic anulus. Because the length of the infundibular septum of tetralogy of Fallot is $14 \% \pm 7 \%$ of the right ventricular length, ${ }^{5}$ a short ventriculotomy with approximate $30 \%$ of the right ventricular length could be enough. At the area of the junction between the aortic valve and ventriculoinfundibular fold, the bases of all muscle bundles are left as muscular stumps after resection (Fig. 1, $A$ ). Therefore all pledget-supported mattress sutures are stitched precisely from endocardium to endocardium (Number 6 suture in Fig. 5). The outlets of the sutures form a line along the junction between the aortic valve and ventriculoinfundibular fold. Pledgets are placed at the base of stumps or in the crevices between the muscle bundles. Careful suturing is mandatory to prevent residual leakage in this particular area. Sutures were either 5-0 polypropylene with a polytetrafluoroethylene (PTFE, $0.4 \mathrm{~mm}$ in thickness) pledget of $2 \times 4 \mathrm{~mm}$ in size or $4-0$ with a PTFE pledget of $2.5 \times 6.5 \mathrm{~mm}$ in the very early patients; then $6-0$ with a PTFE pledget of $1.5 \times 3 \mathrm{~mm}$ was adopted as well in most remaining patients.

The monocusp was made of porcine pericardium ${ }^{1}$ in the initial 100 patients and of PTFE (0.1 mm in thickness) ${ }^{6}$ in the remaining recent patients. The width of the cusp was $30 \%$ to $40 \%$ of the right ventricular length in the initial series and $35 \%$ to $50 \%$ in the recent series. The length of ventriculotomy and patch infundibuloplasty below the monocusp was less than $30 \%$ of the right ventricular length (Fig. 1, B). Both the width of cusp and the length of patch were calculated before operation by the formula: Right ventricular length $(\mathrm{cm})=4.28 \times$ BSA (body surface area, $\left.\mathrm{m}^{2}\right)+3.66$. This formula was introduced from the measurement in 35 heart specimens with tetralogy of Fallot and in 65 patients with Fallot's tetralogy under anoxic and cold arrest perioperatively in 1972 and $1973 .{ }^{5}$

In patients with pulmonary atresia, the cavity of the blind-ended pulmonary trunk was approximated and sutured to the superior edge of the ventriculotomy in most cases; an atretic membranous valve was incised in some cases, followed by placement of a lozenge-shaped patch with a large cusp for reconstruction of the outflow tract (Fig. 6, right).

\section{Midterm results}

Associated conditions. At the time of operation the age of 233 patients ranged from 2 months to 53 years, with a mean of 4.6 years. Of the patients $44 \%$ were younger than 2 years of age, and $11 \%$ were less than 12 months of age. Eight percent were older than 10 years of age. Among the most recent 100 


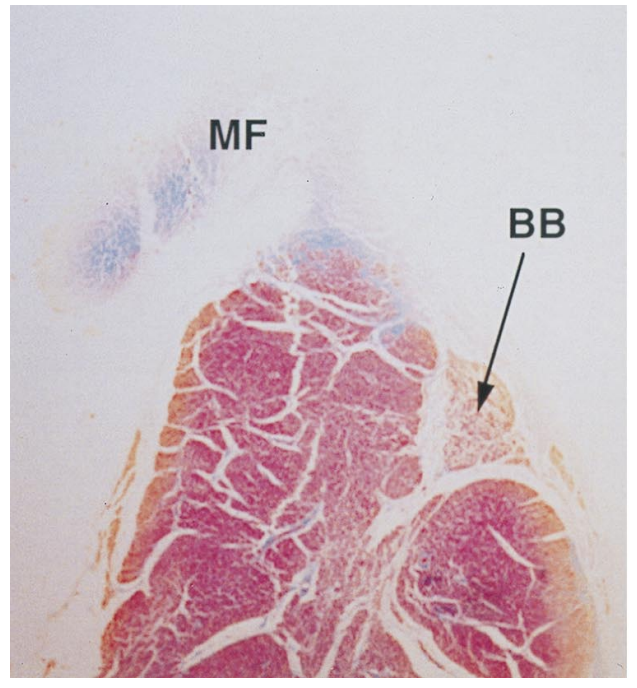

A

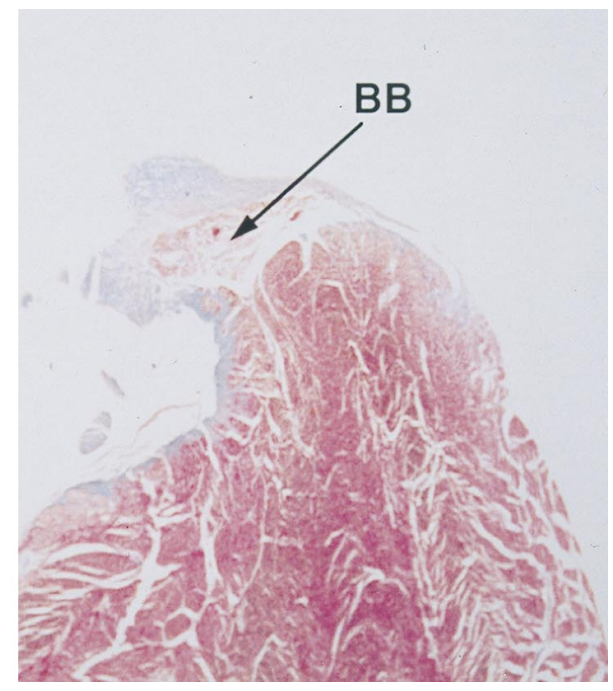

B

Fig. 3. Microscopic pictures of the same hearts as shown in Fig. 1. The left side is the right ventricle and the right side is the left ventricle. A, Case with a membranous flap. Branching bundle $(B B)$ is subendocardial on the left aspect of the ventricular septum. A membranous flap is on the crest of the ventricular septum and remote from the branching bundle. B, Case without a membranous flap. The branching bundle appears on the crest of the ventricular septum.

patients, $56 \%$ were younger than 2 years of age. Pulmonary artery index by Nakata ${ }^{7}$ was $282 \pm 126$ $(n=161)$. A membranous flap at the posteroinferior border of VSD was present in 202 patients (86\%), 28 patients $(12 \%)$ had a muscle bar between the defect and the tricuspid valve, and only 3 patients $(2 \%)$ had neither a membranous flap nor a muscle bar. Fifty-five patients (24\%) previously underwent palliative operation, including aortopulmonary shunt and unifocalization. Coexisting pulmonary atresia rather than pulmonary stenosis was found in 21 patients. Unifocalization procedures for major aortopulmonary collateral arteries (MAPCA) had been previously performed in five patients, and a ligation of MAPCA was performed concomitantly in one.

Of the patients, 45 required patch enlargement of the distal pulmonary artery, mostly in the left pulmonary artery, but occasionally both left and right pulmonary arteries. The reasons for pulmonary distortion were either presence of an opened or closed duct in 27, previous construction of Blalock-Taussig shunt in 16 (representing 34\% of all patients with this shunt), and Waterston shunt in two. Two patients underwent percutaneous balloon dilatation for left pulmonary stenosis after the surgical repair.

Anomalous coronary artery across the outflow tract of the right ventricle was found in one 2-year- old patient. A transannular patch with a wide PTFE monocusp of which the length of the infundibuloplasty was very short was used for repair.

Four patients had partially anomalous pulmonary venous connections. One had atrioventricular septal defect. One had coexisting divided left atrium (cor triatriatum $).{ }^{8}$ Partially anomalous pulmonary venous connection in two patients, atrioventricular septal defect, and cor triatriatum were concomitantly repaired and all have had a good postoperative course.

Mortality and reoperation. No incidence of early death occurred, and only two late deaths occurred (late mortality $=0.9 \%$ ) over a mean follow-up period of 7.3 years. The first death was due to pneumonia, which occurred after reoperation for residual partially anomalous pulmonary venous connection (Ib and IIb type). The second patient had left heart failure, caused by injury to the left anterior descending coronary artery during division of pericardial adhesions, and died 1 year after operation. Eleven years postoperatively, actuarial survival was $99.1 \%$.

No patient required reoperation for residual VSD, residual outflow obstruction, or replacement of patch or monocusp. Only two patients were reoperated on for residual partially anomalous pulmonary venous connection. Concomitant repair of 


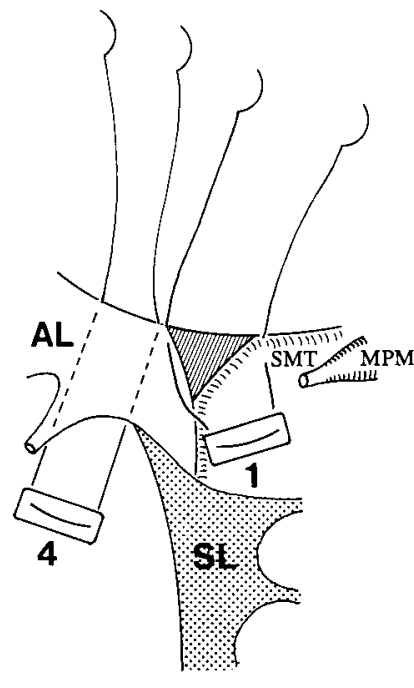

A

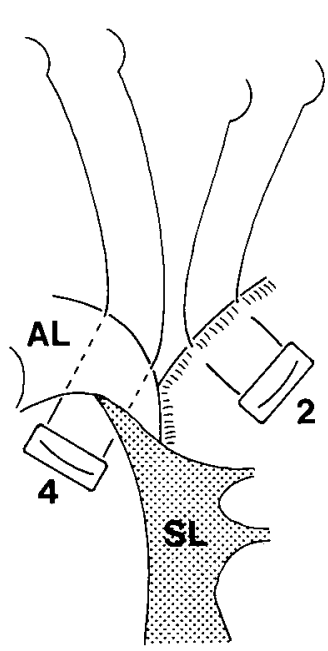

B
Fig. 4. Two types of perimembranous outlet VSD in tetralogy of Fallot. The number of the sutures correspond to the number in Fig. 5. A. An "interventricular" membranous flap (shaded triangle) exists at the posteroinferior border of the VSD. Number 1 suture is stitched through the fibrous tissue of the septal leaflet at the junction with the membranous flap and through the muscular margin of the posterior extension of the septomarginal trabeculation (SMT) at the junction with the membranous flap. The membranous flap is indirectly used and is reinforced by a pledget. Number 4 suture is placed through the anulus of the anterior leaflet of the tricuspid valve corresponding to the fibrous continuity with the aortic noncoronary cusp. The medial papillary muscle $(M P M)$ is divided for convenience. B, The membranous flap is absent. Number 1 suture is simply skipped.

the anomalous veins had been achieved in the other two patients as mentioned above.

Postoperative morbidity. All 233 patients were in sinus rhythm postoperatively, without any incidence of heart block. A solitary patient had temporary Wenckebach heart block develop after operation, which eventually became sinus rhythm 3 months postoperatively. In this patient the membranous flap had been absent as in Figs. 2, B, 3, B, and 4, $B$. Approximately half of the patients had right bundle branch block. No patient had congestive heart failure develop, except for two late deaths, or a significant residual VSD requiring reoperation.

One third of all patients were carefully examined for heart murmurs in the late period. No or trivial systolic murmurs were found in $84 \%$ of patients, whereas no or trivial diastolic murmurs were discov-

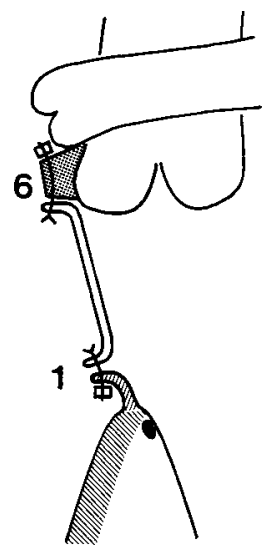

A

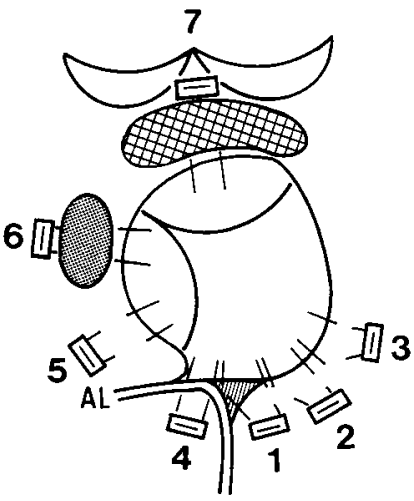

SL
B

Fig. 5. Sutures for patching the VSD: 1, at the membranous flap; 2, in the posterior extension of septomarginal trabeculation; 3 , in the anterior limb of septomarginal trabeculation; 4, through the anterior "anulus" of the tricuspid valve, corresponding to the fibrous continuity with the aortic noncoronay cusp; 5 , in the nonresected ventriculoinfundibular fold; 6 , in the muscle stump after resection of hypertrophied muscle bundles; 7 , in the subtotally resected infundibular septum. $A L$ and $S L=$ the anuli of the anterior and septal leaflets of the tricuspid valve, respectively.

ered in $93 \%$. The minority of the initial 100 patients in whom repair was done with a porcine pericardial monocusp exhibited a second pulmonary sound in the late phase. On the other hand, most patients undergoing repair with the PTFE monocusp did have an audible distinct second pulmonary sound.

Hemodynamics I: Echocardiography. Thirtythree patients who underwent repair with a PTFE monocusp were evaluated by echocardiography. The period between the operation and the echocardiographic study was $2.4 \pm 1.6$ years $(n=33)$. The mobility of the monocusp was detected in 28 patients $(85 \%)$. Pulmonary regurgitation was not present in 9 patients, trivial in 3, mild in 15, and moderate in 6 . The pressure gradient across the pulmonary valve was $14.3 \pm 6.3 \mathrm{~mm} \mathrm{Hg}(n=33)$. Tricuspid valve regurgitation was echocardiographically absent in 23 patients (70\%), trivial in 6 , mild in 3 , and moderate in 1 in whom atrioventricular septal defect was concomitantly repaired.

Hemodynamics II: Catheterization. The ratio of right-to-left ventricular pressure was measured immediately after cardiopulmonary bypass during operation (early $\mathrm{RV} / \mathrm{LV}$ ) in 174 patients and was measured by catheterization from several months to 


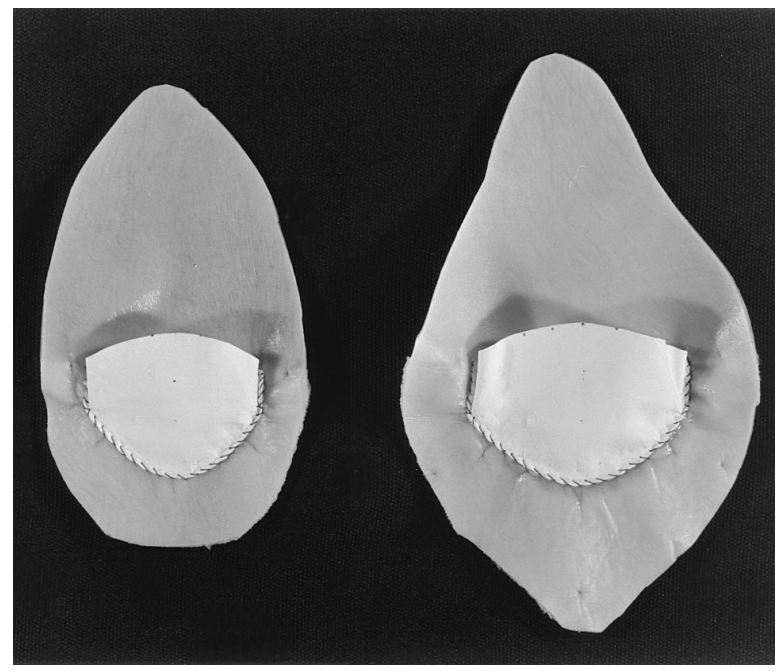

Fig. 6. PTFE $(0.1 \mathrm{~mm})$ monocusp patch. Left, An example of the usual patch. Right, A lozenge-shaped patch used in patients with pulmonary atresia.

1 year after operation (late $\mathrm{RV} / \mathrm{LV}$ ) in 60 patients of the whole series. The early RV/LV was $0.54 \pm 0.18$ $(n=174)$ and the late $\mathrm{RV} / \mathrm{LV}$ was $0.44 \pm 0.13(n=$ 60). The patients in whom the late RV/LV and the late CVP were simultaneously measured by catheterization were then subdivided into those operated on in the initial series with a xenopericardial monocusp and those in the most recent series with a PTFE monocusp. In 26 patients with a xenopericardial monocusp, catheterization was performed one to several months after operation, the late $\mathrm{RV} / \mathrm{LV}$ was $0.48 \pm 0.11(n=26)$, and the late CVP was $8.7 \pm 2.6 \mathrm{~mm} \mathrm{Hg}(n=26)$. In 30 patients with a wide PTFE monocusp, catheterization was performed several months to 1 year after operation, the late $\mathrm{RV} / \mathrm{LV}$ was $0.40 \pm 0.14(n=30)(p=0.05)$, and the late CVP was $5.6 \pm 2.2 \mathrm{~mm} \mathrm{Hg}(n=30)(p=0.001)$. Both the late $\mathrm{RV} / \mathrm{LV}$ and the late CVP were significantly lower in the patients with a PTFE monocusp than in those with a xenopericardial monocusp. Among the 100 most recent patients, $56 \%$ were less than the age of 24 months at operation. Among these, the late RV/LV was $0.41 \pm 0.09$ $(n=19)$ and the late CVP was $6.1 \pm 2.0 \mathrm{~mm} \mathrm{Hg}$. In patients with pulmonary atresia of whole series, the early RV/LV was $0.68 \pm 0.15(n=14)$ and the early CVP was $8.0 \pm 2.7 \mathrm{~mm} \mathrm{Hg}(n=10)$, whereas the late $\mathrm{RV} / \mathrm{LV}$ was $0.68 \pm 0.22(n=3)$ and the late CVP was $6.7 \pm 3.9 \mathrm{~mm} \mathrm{Hg}(n=3)$.

Residual pressure gradient across the valve and the outflow tract was $12.8 \pm 9.8 \mathrm{~mm} \mathrm{Hg}$ in 55 patients who underwent postoperative catheterization. No patients required reoperation for residual outflow obstruction of the right ventricle thus far. High RV/LV was mostly found in patients with pulmonary atresia and distal pulmonary narrowing.

Ventricular volume was measured angiographically before and several months to 1 year postoperatively. The right ventricular end-diastolic volume (RVEDV) and the left ventricular end-diastolic volume (LVEDV) did not change significantly in the late phase in the consecutive 30 patients less than 2 years of age undergoing operation with a xenopericardial monocusp. ${ }^{9}$ In the recent patients with a PTFE monocusp, the late RVEDV was $91.8 \% \pm$ $29.5 \% \mathrm{~N}(n=12)$ and the late LVEDV was $115 \% \pm$ $30.6 \% \mathrm{~N}(n=12)$. Both the RVEDV and the LVEDV did not significantly increase at the late stage. The late right ventricular ejection fraction was $54.7 \% \pm 8.2 \%$, and the late left ventricular ejection fraction was $61.1 \% \pm 6.5 \%$.

Hemodynamics III: Pressure-volume loop. In the recent series, the left ventricular function was analyzed by studying the pressure-volume loop ${ }^{10}$ during operation immediately before and after cardiopulmonary bypass with small doses of inotropic agents in 25 patients with a mean age of 3.6 years (Fig. 7). The pressure-volume loop was obtained by a catheter-tipped manometer in the left ventricle and echocardiography from the surface of the heart. The LVEDV increased from $90 \% \pm 11 \%$ of normal $(\mathrm{N})$ to $133 \% \pm 19 \% \mathrm{~N}(p=0.01)$. The external work index increased from $35 \pm 8 \mathrm{gm} / \mathrm{m}^{2}$ body surface area to $75 \pm 16 \mathrm{gm} / \mathrm{m}^{2}$ body surface area $(p=0.01)$. The pressure volume area index increased from $100 \pm 18 \mathrm{gm} / \mathrm{m}^{2}$ body surface area to $153 \pm 22$ $\mathrm{gm} / \mathrm{m}^{2}$ body surface area $(p=0.01)$. The $\mathrm{E}_{\max }$ decreased from $2.0 \pm 0.2 \mathrm{~mm} \mathrm{Hg} / \mathrm{ml}$ to $1.6 \pm 0.2$ $\mathrm{mm} \mathrm{Hg} / \mathrm{ml}(p=0.01)$. However, the ejection fraction increased from $63 \% \pm 5 \%$ to $74 \% \pm 4 \%(p=$ 0.01 ). Mechanical efficiency (external work index/ pressure volume area index) increased from $37 \% \pm$ $10 \%$ to $50 \% \pm 12 \%(p=0.01)($ Table I).

\section{Discussion}

Because of the diastolic right-to-left "interventricular" (not ventriculoaortic) shunt ${ }^{11}$ and the diminished pulmonary venous return caused by right ventricular outflow obstruction, both the RVEDV and the LVEDV are mostly subnormal in patients with tetralogy of Fallot. ${ }^{12}$ In addition, the aortic flow ejected by both ventricles has to sustain the normal systemic circulation and has to supply systemic- 
Tetralogy of Fallot

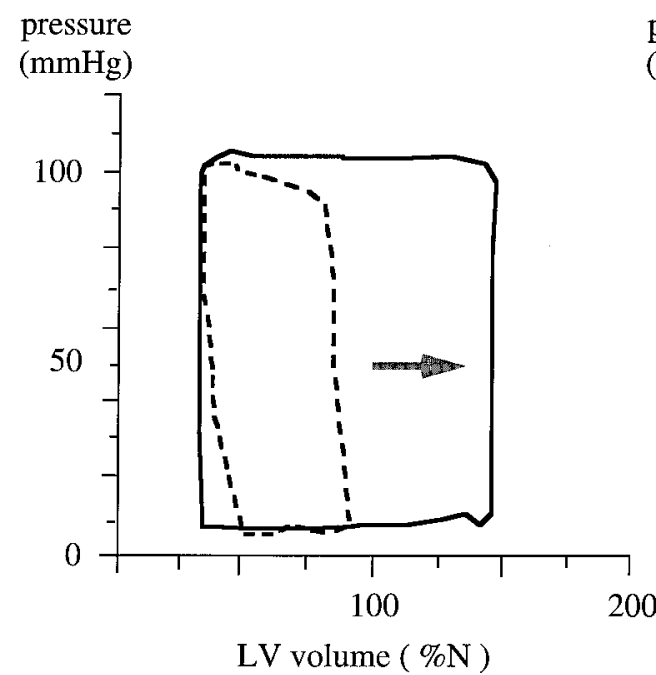

Ventricular Septal Defect

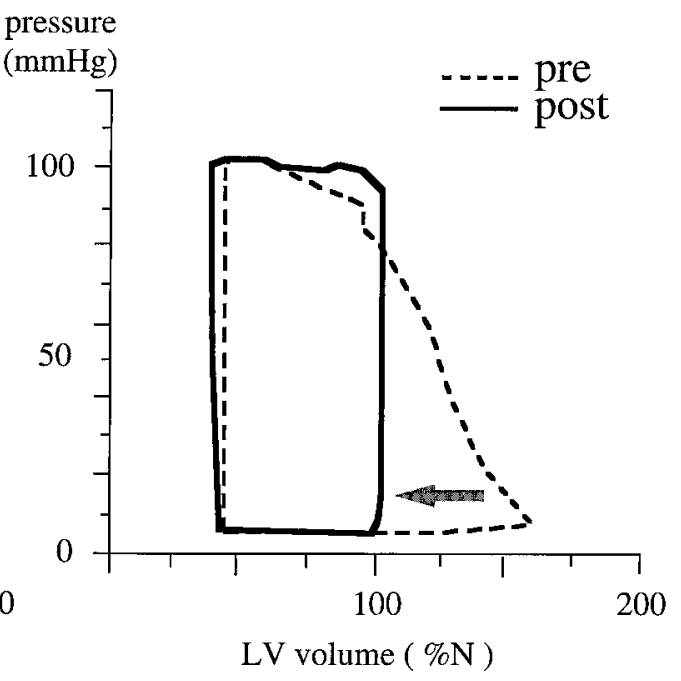

Fig. 7. Pressure-volume loops of the left ventricle immediately before and immediately after operation. Left, Tetralogy of Fallot. The loop shifts to the right after repair. Right, Isolated VSD. The loop shifts to the left after repair.

pulmonary collateral arteries, as well as widely dilated systemic vascular beds, to cope with hypoxemia. These conditions do not change immediately after operation despite the fact that both ventricles have to work individually. The volume overload of both ventricles therefore inevitably increases immediately after repair. Compensations for the suddenly increased loading in the LVEDV, external work index, pressure volume area index, and the decrease of $\mathrm{E}_{\max }$ are partly achieved by the increase of ejection fraction and mechanical efficiency under inotropic support immediately after operation. Chronic compensation is further necessary. The same situation exists in the right ventricle in terms of volume overload. These hemodynamic characteristics are in striking contrast to the situation encountered in patients with isolated VSD. Accordingly, patients with tetralogy of Fallot require precise repair in which all extra factors increasing the volume overload in both ventricles and elevating the CVP should be avoided to provide easier compensation. Those extra factors involve the residual VSD, a heart block, the diastolic fixation of the septal leaflet of the tricuspid valve, a pulmonary and tricuspid regurgitation, the residual outflow obstruction, and the impaired ventricular contractility. Residual VSD is one of the major postoperative sequelae; it markedly increases the ventricular volume in patients with tetralogy of Fallot. By the
Table I. Data from pressure volume loop of left ventricle during operation

\begin{tabular}{lcc}
\hline & Before CPB & After CPB \\
\hline $\begin{array}{l}\text { End-diastolic volume (\% of } \\
\text { normal) }\end{array}$ & $90 \pm 11$ & $133 \pm 19$ \\
$\quad \begin{array}{l}\text { End-systolic volume (\% of } \\
\text { normal) }\end{array}$ & $33 \pm 3$ & $35 \pm 2$ \\
$\quad \begin{array}{l}\text { External work index } \\
\quad\left(\mathrm{gm} / \mathrm{m}^{2} \mathrm{BSA}\right)\end{array}$ & $35 \pm 8$ & $75 \pm 16$ \\
$\begin{array}{l}\text { Pressure volume area index } \\
\quad\left(\mathrm{gm} / \mathrm{m}^{2} \mathrm{BSA}\right)\end{array}$ & $100 \pm 18$ & $153 \pm 22$ \\
$\mathrm{E}_{\text {max }}(\mathrm{mm} \mathrm{Hg} / \mathrm{ml})$ & $2.1 \pm 0.2$ & $1.6 \pm 0.2$ \\
$\quad$ Ejection fraction $(\%)$ & $63 \pm 5$ & $74 \pm 4$ \\
$\quad$ Mechanical efficiency $(\%)$ & $37 \pm 10$ & $50 \pm 12$ \\
\hline
\end{tabular}

$C P B$, Cardiopulmonary bypass; $B S A$, body surface area.

same token associated anomalous pulmonary venous connection should be concomitantly repaired. If not, it will result in a significant increase in the right ventricular volume load because of increased pulmonary flow postoperatively. By eliminating all these potential risks, it is possible to achieve the ultimate goal with a low atrial pressure.

Because of the reduced volume load combined with the increased pressure load of the systemic ventricle, the right ventricle develops concentric hypertrophy preoperatively. The subaortic VSD is the major outlet of the right ventricle in tetralogy of Fallot and, hence, the VSD is always outlet type and 
is either perimembranous or muscular. The conditions alluded to eventually provide a "thick" posterior extension of the septomarginal trabecula, supporting the medial papillary muscle and a membranous flap located on the inferior border of the VSD. At the same time this thick muscular layer also covers the right aspect of the main atrioventricular conduction axis, resulting in the left-sided location of the branching bundle in most patients. ${ }^{3}$ This arrangement is not as frequent in other congenital heart malformations, such as complete transposition, double-outlet right ventricle, and isolated VSD. ${ }^{2}$ Moreover, because of this specific morphologic configuration in tetralogy of Fallot, the membranous flap can be safely used as an anchor for sutures during closure of the $\mathrm{VSD},{ }^{4}$ unless, of course, the rare situation prevails in which the membranous flap is absent. Although the membranous flap has not always been seen by others, ${ }^{13}$ careful observation in this series showed the structure to exist in $98.5 \%$ (202 of 205) of patients with a perimembranous VSD. It was absent in only three patients. If the membranous flap is fused to the medial papillary muscle (the so-called "pseudoflap" $\left.{ }^{13}\right)$, the thick posterior extension of the septomarginal trabeculation supports both the medial papillary muscle and the membranous flap as in Fig. $3, A$. This makes it easy to place sutures in the membranous flap. If the membranous flap is a curtain on the ventricular aspect of the septal leaflet of the tricuspid valve (the so-called real flap ${ }^{11}$ ), the flap is separated from the medial papillary muscle and the support from the posterior extension of the septomarginal trabeculation is less prominent. In those instances the flap can still be used, but precise suturing is required as in Fig. 4, $A$, so that the septal leaflet of the tricuspid valve is not used anymore.

Fixation of the "septal leaflet" of the tricuspid valve disturbs the bulging of the leaflet at the end of ventricular diastolic phase. This restraint of the septal leaflet unexpectedly decreases the right ventricular end-diastolic capacity, resulting in an elevation of the right ventricular end-diastolic pressure. Furthermore, this restraint could be one of the reasons for tricuspid regurgitation in the late period. In fact, one of the advantages to use of the membranous flap is to leave the "septal leaflet" intact. As a consequence, the septal leaflet remains mobile with perfectly preserved diastolic and systolic functions, whereas heart block and residual VSD are entirely prevented. This is the most important advantage of conotruncal repair. The fact that the late RVEDV and the late CVP were within preoperative range indicates that the right ventricle did not have any significant residual VSD or tricuspid dysfunction such as a regurgitation or a fixation of the septal leaflet. Excessive enlargement of the right ventricle with RVEDV greater than $200 \%$ of normal because of the residual VSD or other reasons may induce the secondary tricuspid regurgitation. ${ }^{14}$ The very fact of suturing to the septal "leaflet," not "anulus," of the tricuspid valve to prevent heart block and residual leakage can be one of the reasons promoting late tricuspid regurgitation.

The anatomy of the right bundle branch is quite variable. ${ }^{15}$ Right bundle branch block could occasionally be avoided, for instance in cases in which a thick septomarginal trabeculation covers the proximal part of the right bundle branch. Although suturing to the very edge of VSD by minute single suture may prevent right bundle branch block, ${ }^{16}$ superficial sutures might also promote residual leakage at the site of patching VSD or heart block. If the membranous flap is absent as in Fig. 3, $B$, direct suturing to the very edge of the septum counts the risk of inducing not only right bundle branch block but also bifascicular block with left axis deviation or trifascicular block, which are more serious conditions. ${ }^{17,18}$

Direct connection of the aortic valve to the ventriculoinfundibular fold is another of the essential consequences of aortic overriding in tetralogy of Fallot. Because of this, it is preferable (1) to resect carefully hypertrophied muscle bundles, leaving muscle stumps intact (Fig. 1, A) and (2) to suture finely from endocardium to endocardium, placing pledgets within crevices between muscle bundles thus forming a line of the outlets of the sutures along the junction between the aortic valve and ventriculoinfundibular fold (Fig. 5). Both procedures can be performed easily and with precision through a short ventriculotomy. Careful execution of both procedures could completely prevent residual VSD, which has been frequently reported to occur in this particular area. ${ }^{19}$ With a transatrial approach, it appears more difficult to achieve these goals without causing stretch damage to the tricuspid valve.

The short patch with a wide monocusp satisfactorily released the outflow obstruction of the right ventricle. Residual pressure gradient across the valve and the outflow tract of the right ventricle was not significant; therefore no patients required reoperation for residual outflow obstruction. Postoperative pulmonary regurgitation was not a prominent feature in this series. The precise closure of the VSD 
using smaller sutures, such as 6-0 with a tiny pledget, and the reconstruction of the outflow tract using the wider PTFE monocusp further decreased the late $\mathrm{RV} / \mathrm{LV}$ pressure ratio and the late CVP in the recent series comparable to the initial series with a xenopericardial monocusp. This improvement might be related as well to a different interval between the repair and the catheterization, which was longer in the patients with a PTFE monocusp than those with a xenopericardial monocusp. No patients required reoperation for replacement of the monocusp. Although no evidence exists of calcification of the xenopericardial patch and monocusp and the PTFE monocusp on echocardiography or radiography so far, the long-term function of those monocusps could not be superior to that of a natural pulmonary valve; thus a careful long-term observation is necessary.

Late RVEDV and LVEDV did not change significantly and were almost within normal range despite strikingly increased volume load immediately after repair. Inotropic support increased ejection fraction and, as a consequence, decreased enddiastolic pressures of both ventricles immediately after repair. In a combination of conotruncal repair and mild inotropic support, the suddenly increased volume load could be gradually compensated and eventually returned to the normal range during the midterm follow-up.

Although the use of a lozenge-shape patch provides a smooth outflow of the right ventricle, which will be expected to grow when compared with the procedures with an extracardiac conduits, further efforts are required to reduce the late $\mathrm{RV} / \mathrm{LV}$ pressure ratios in cases of pulmonary atresia with or without MAPCAs. In addition to conventional twostaged repair procedures, ${ }^{20}$ a combined approach using operation and interventional catheterization has recently been reported. ${ }^{21}$ Primary unifocalization in the neonate ${ }^{22}$ and early establishment of central pulmonary arterial flow ${ }^{23}$ might well provide better long-term hemodynamics.

Repair of tetralogy of Fallot in infancy ${ }^{24}$ and in neonate ${ }^{25}$ has also been reported. Mortality and the need for reoperation, nonetheless, were relatively high. We do not advocate neonatal repair because usually there is infrequent significant clinical urgency and because we believe that insufficient surgical skill may cause too high an incidence of residual VSD and heart block in this very young group.

Our experiences with conotruncal repair in patients younger than 2 years of age, with no hospital deaths, only one late death after reoperation for residual anomalous pulmonary venous connection, no heart block, no residual VSD, a low late RV/LV pressure ratio, a low late CVP, and well-preserved ventricular function, lead us to recommend the elective repair in infancy and in patients less than 2 years of age.

\section{Conclusion}

Conotruncal repair, which consists, first, of a precise closure of the VSD using the membranous flap instead of the septal leaflet of the tricuspid valve and, second, reconstruction of the outflow tract of the right ventricle by a wide monocusp patch, has provided good midterm results with a low CVP, minimum heart murmur, and well-reconstructed outflow tract of the right ventricle, without a heart block, the residual VSD, and the volume overload in the ventricles.

\section{REFERENCES}

1. Kurosawa H, Imai Y, Nakazawa M, Momma K, Takao A. Conotruncal repair of tetralogy of Fallot. Ann Thorac Surg 1988;45:661-6.

2. Kurosawa H, Becker AE. Tetralogy of Fallot. In: Atriovenricular conduction in congenital heart disease-surgical anatomy. Tokyo: Springer Verlarg; 1987. p. 97-144.

3. Kurosawa H, Becker AE. Modification of the precise relationship of the atrioventricular conduction bundle to the margins of the ventricular septal defects by the trabecula septomarginalis. J Thorac Cardiovasc Surg 1984;87:605-15.

4. Kurosawa H, Imai Y, Becker AE. Surgical anatomy of the atrioventricular conduction bundle in tetralogy of Fallot: new findings relevant to the position of the sutures. J Thorac Cardiovasc Surg 1988;95:586-91.

5. Kurosawa H, Imai , Nakazawa M, Takao A. Standardized patch infundibuloplasty for tetralogy of Fallot. J Thorac Cardiovasc Surg 1986;92:396-401.

6. Yamagishi M, Kurosawa H. Outflow reconstruction of tetralogy of Fallot using a Gore-Tex valve. Ann Thorac Surg 1993;46:1090-3.

7. Nakata S, Imai Y, Takanashi Y, et al. A new method for the quantitative standardization of cross-sectional areas of the pulmonary arteries in congenital heart diseases with decreased pulmonary blood flow. J Thorac Cardiovasc Surg 1984;88:610-19.

8. Nomura K, Kurosawa H, Morita K, Miyamoto H, Tatara A. A surgical report: rare association of tetralogy of Fallot with cor triatriatum, unroofed coronary sinus and persistent left superior vena cava. J Jpn Assoc Thorac Surg 1997;45:92-5.

9. Nagatsu M, Kurosawa H, Imai Y, et al. Conotruncal repair of tetralogy of Fallot under the age of 2 years. J Jpn Assoc Thorac Surg 1991;39:1017-23.

10. Suga H, Sagawa K, Shoukas AA. Load independence of the instantaneous pressure-volume ratio of the canine left ventricle and effects of epinephrine and heart rate on the ratio. Circ Res 1973;32:314-22.

11. Jarmakani MM, Edwards SB, Spach MS, et al. Left ventricular pressure-volume characteristics in congenital heart disease. Circulation 1968;37:879-89. 
12. Jarmakani JM, Nakazawa M, Jones JI, Marks RA. Right ventricular function in children with tetralogy of Fallot before and after aortic-to-pulmonary shunt. Circulation 1976; 53:555-61.

13. Suzuki A, Ho SY, Anderson RH, Deanfield JE. Further morphologic studies on tetralogy of Fallot, with particular emphasis on the prevalence and structure of the membranous flap. J Thorac Cardiovasc Surg 1990;99:528-35.

14. Kobayashi J, Kawashima Y, Matsuda H, et al. Prevalence and risk factors of tricuspid regurgitation for correction of tetralogy of Fallot. J Thorac Cardiovasc Surg 1991;102:611-6.

15. Kurosawa H, Becker AE. Surgical anatomy of the right bundle branch. Kyobugeka 1982;35:179-87.

16. Hazan E, Bical O, Bex JP, et al. Is right bundle branch block avoidable in surgical correction of tetralogy of Fallot. Circulation 1980;62:852-4.

17. Godman MJ, Roberts NK, Izukawa T. Late postoperative conduction disturbances after repair of ventricular septal defect and tetralogy of Fallot. Circulation 1974;49:214-21.

18. Yabek SM, Jarmakani JM, Roberts NK. Diagnosis of trifascicular damage following tetralogy of Fallot and ventricular septal defect repair. Circulation 1977;55:23-7.

19. Preminger TJ, Sanders SP, van de Velde ME, Castaneda AR, Lock JE. "Intramural" residual interventricular defects after repair of conotruncal malformations. Circulation 1994;89: 236-42.

20. Sawatari K, Imai Y, Kurosawa H, Isomatsu Y, Momma K. Staged operation for pulmonary atresia and ventricular septal defect with major aortopulmonary collateral arteries: new technique for complete unifocalization. J Thorac Cardiovasc Surg 1989;98:738-50.

21. Rome JJ, Mayer JE, Castaneda AR, Lock JE. Tetralogy of Fallot with pulmonary atresia: rehabilitation of diminutive pulmonary arteries. Circulation 1993;88:1691-8.

22. Shanley CJ, Lupinetti FM, Shah NL, Beekman III RH, Crowley DC, Bove EL. Primary unifocalization for the absence of intrapericardial pulmonary arteries in the neonate. J Thorac Cardiovasc Surg 1993;106:237-47.

23. Pagani FD, Cheatham JP, Beekman III RH, Lloyd TR, Mosca RS, Bove EL. The management of tetralogy of Fallot with pulmonary atresia and diminutive pulmonary arteries. J Thorac Cardiovasc Surg 1995;110:1521-33.

24. Walsh EP, Rockenmacher S, Keane JF, Hougen TJ, Lock JE, Castaneda AR. Late results in patients with tetralogy of Fallot repaired during infancy. Circulation 1988;77:1062-7.

25. Di Donato RM, Jonas RA, Lang P, Rome JJ, Mayer JE Jr, Castaneda AR. Neonatal repair of tetralogy of Fallot with and without pulmonary atresia. J Thorac Cardiovasc Surg 1991;101:126-37.

\section{Discussion}

Dr. Gary K. Lofland (Kansas City, Mo.). In their paper, Professor Kurosawa and colleagues have nicely defined the anatomy of the conotruncal region and demonstrated the usefulness of precise anatomic definition and meticulous technique in achieving complete closure of the ventricular septal defect while avoiding conduction tissue. They should be congratulated on their outstanding clinical results.

They have also demonstrated the usefulness of a mo- nocusp valve in reducing pulmonary insufficiency and improving right ventricular function in the immediate postoperative period. I have also used a monocusp valve in my practice if a small pulmonary valve anulus necessitates a transannular incision. I use a broadly based triangular piece of autologous pericardium, two sides of which are anastomosed to the free edge of the infundibulum, leaving the broad third side to fall down into the concavity created by the transannular incision. A second patch of pericardium or PTFE is then used to reconstruct the right ventricular outflow tract in the traditional manner. I learned this trick from Steve Gundry and Leonard Bailey.

(Slide) This is a slide of a patch that Keith Ashcraft and Tom Holder had been using in Kansas City for about 15 years now, and it looks remarkably similar to Professor Kurosawa's, illustrating further that great minds do indeed think alike. The patch is made of PTFE, whereas the monocusp valve is constructed from autologous pericardium. Now, the pericardial valve in this case is a gradually disappearing structure that eventually sticks open, but it certainly is believed to help right ventricular function in the immediate postoperative period.

Dr. John W. Brown (Indianapolis, Ind.). I would like to compliment the authors on this innovative approach to tetralogy of Fallot. At Indiana University, my colleague Mark Turrentine and I have used a PTFE monocusp to reconstruct the right ventricular outflow tract in this subset of patients with tetralogy who require a transannular patch. We have found reconstruction of the right ventricular outflow tract with this PTFE monocusp has significantly reduced the ICU and hospital stay in that subset. Have you documented in any randomized way that the conotruncal repair is superior to the more conventional transatrial repair? Furthermore, have you documented that the PTFE monocusp improves cardiac output postoperatively?

Dr. Kurosawa. Professor Lofland, Professor Brown, thank you very much for your comments. I would agree with your opinion regarding the monocusp. In the initial series of the conotruncal repair, we used the monocusp made by preserved xenopericardium. After several years of the operation, we found that the pericardial monocusp did not work anymore. However, when we changed our method in which the monocusp was made by PTFE, what we found is that almost all patients showed good motion of the PTFE monocusp on echocardiography. So, in our experience, we have no reason to deny the use of the PTFE monocusp. Although we have not compared the conotruncal repair with the transatrial repair and have not documented an improvement of the cardiac output by the PTFE monocusp, the conotruncal repair apparently prevented volume overload in both ventricles. It is particularly important to note that significant increases of the volume load in the ventricles are caused by several reasons immediately after repair. Therefore I would confidently recommend the precise closure of the ventricular septal defect and use of the monocusp, both of which could provide a good function of the ventricles after repair of tetralogy of Fallot. 